\title{
Abordagem fenomenológica existencial: da educação formal às relações sociais na vida
}

Existential phenomenological approach: from formal education to social relations in life

Elcie F. Salzano Masini ${ }^{1}$

\section{Resumo}

Com trajetória pessoal na área da Educação e Psicologia - variantes do método fenomenológico -, Masini (1984) estendeu o embasamento de Boss, da Daseinsanalyse, à educação escolar sobre o "aproximar-se" do aluno e sua possibilidade de compreender e desvelou que emergia das relações que este fazia em suas condições existenciais de vida. O "aproximar-se" do aluno com deficiência visual (DV) evidenciou desconsideração à sua percepção ao ser estudado a partir das pessoas videntes. Masini (1994) buscou compreender essa problemática pesquisando o perceber de pessoas com DV, inspirada em Merleau-Ponty (1971), desvelando a riqueza do uso dos outros sentidos que ampliaram o perceber dos que dispõem de todos os sentidos, em Projetos em diversas universidades: FEUSP, 20142016; Unimarco, 1994; UPM, 2010-2016 e Diretório de Pesquisa CNPq disseminando-se da educação formal para a das relações sociais no mundo vida.

Palavras-chave: Fenomenologia-existencial; educação escolar; vida

\begin{abstract}
Personal way on Educational Psychology, on phenomenological method. Masini (1984) extend the foundation of Boss of Dasseinsanalyse for de school education - to be close of the student and his possibility to understand, revealed that it emerged of his existencial conditions of life. To be close of student with visual impairment (VI) showed inconsiderateness of his perception studied through visual paterns. Masini (1994) tried to understand this problem researching the perception of person VI, inspired by Merleau-Ponty (1971) unveiling the richness of the use of others senses, that amplified the perception of people with all senses, in Projects in divers universities: FEUSP, 2014-2016; Unimarco, 1994; UPM, 2010-2016 and Group of Research of CNPq disseminating the formal education towards social relations on life of world.
\end{abstract}

Keywords: Existencial-phenomenoly; schoolar-education; life

\footnotetext{
${ }^{1}$ Professora associada da Universidade de São Paulo (USP). Professora dos Programas de pós-graduação "Psicologia e Educação" e "Educação Especial”. Professora titular da Universidade Presbiteriana Mackenzie (UPM), de 1998 a 2017 , na pós-graduação da UPM. . São Paulo (SP). Brasil. E - mail: delcie66@yahoo.com.br
}

Recebido: 15/ 02/ 2017

Aceito: 24/ 02 / 2017 
Exponho uma trajetória pessoal na área da Educação e Psicologia em uma caminhada de variantes do método fenomenológico, que emergiu de perguntas ao longo de um trabalho junto a crianças, a jovens e àqueles que lidavam com eles.

O marco inicial desta narrativa foi a insatisfação que experimentei com minha dissertação de mestrado, intitulada "Sistematização e aplicação de recursos facilitadores de aprendizagem significativa, propostos por Ausubel, numa situação de sala de aula" - pesquisa sobre a Aprendizagem Significativa de Ausubel (1963), na área de Biologia com alunos do $2^{\circ}$ grau - mesmo aprovada com nota máxima pela Banca. Meu inconformismo ao verificar que os dados coletados e analisados dos alunos em Biologia restringiam-se à definição de conceitos, desconsiderando o ponto central enfatizado pelo autor - o de verificar o que o aprendiz já sabe para dali introduzir novas informações definiu a diretriz de minha Tese de Doutorado: buscar um caminho para estar junto ao aluno, desvendar seu sentir, pensar, agir, motivos, valores, sua singularidade e especificidade para propiciarlhe condições de compreender o ensinado.

Entre as disciplinas da Pós-Graduação do Doutorado conheci a obra de Minkowski (1968), Le temps vécu, e de Boss (1979), Na noite passada eu sonhei, ficando assinalado para mim: de Minkowski, a abordagem fenomenológica para compreender a experiência vivida, sem perder sua especificidade, sobre os estados de consciência de cada paciente a partir de sua experiência pessoal; de Boss, a abordagem fenomenológica salientando que alcançar o significado de um ser humano, de qualquer coisa no mundo, implica a indissolúvel presença do ente e do campo aberto, pela habilidade de perceber sua significação, para a consciência dessa coisa.

Vislumbrei, na ênfase de Boss à indissolubilidade do ente que pesquisa e do campo (sujeito ou objeto investigado), um caminho para estar junto ao aluno, desvendando sua singularidade e especificidades. Perscrutei a trajetória de Boss (1976) em Psicoterapia, sobre a qual fez sua primeira publicação na década de 50 do século XX, embasado na reflexão filosófica de Heidegger (1962), sobre a análise do existir - do "ser com o outro" e dele "aproximar-se" - Cap. IV de Ser e Tempo. Resgatei dali os seguintes itens que considerei relevantes para o caminho que buscava para atender o aluno: 1) oferecer-se como abertura iluminada pelo perceber e entender significados - dar-se conta do que acontece ao derredor, pela conexão viva do corpo-mundo, em relação de afinada sincronia, e entender a possibilidade pela qual as coisas podem ter significado no mundo de um ser humano; 2) pautar-se por novos caminhos, apoiado na proposta da Daseinsanalyse, fundada por Boss, e outros psiquiatras para a psicoterapia e psicopatologia, cujos fundamentos Boss e Condrau (1976, p. 42) sintetizam: “A fenomenologia baseia-se assim na essência do homem, enquanto ele é constituído por uma disponibilidade fundamental para o aparecer das coisas e solicitado a lhes oferecer o lugar de abertura constitutivo de sua presença na qual elas podem se apresentar".

Concepção essa que Spanoudis (1978, p. 7-9) tornou mais clara ao afirmar: "[...] é um método para que nos aproximemos do existir humano e passemos a compreendê-lo. Nesse sentido é uma fenomenologia hermenêutica que nos possibilite ver os fenômenos como eles se mostram e desvelar o sentido fundamental de tudo que encontramos".

Esclareceu-me que a abertura ao mundo (ao outro) é constituída pela sintonia de um estado de espírito que tem a ver com o outro, ao atendê-lo e cuidar dele, dizendo respeito à característica do existir humano: "o Aproximar-se", que implica motivação, conforme explicita Boss (1979): "A significação e compreensão só existem no domínio das relações motivadas que constituem a vida humana” (p. 58). 
Do Projeto de Doutorado, coparticiparam supervisora (eu, como pesquisadora) e aconselhadoras (pesquisadas), buscando: 1) Compreender o que propiciava às pesquisadas ampliar seus horizontes reencontrando suas próprias possibilidades e o que as limitava no atendimento ao aluno. 2) Construir, conjuntamente, supervisora e aconselhadoras, uma proposta de aconselhamento para atender ao item 1). Essa proposta compôs-se de três etapas: a) De questionamento e ação, da qual participaram aconselhadoras e supervisora, sendo a matéria-prima o vivido nas situações de aconselhamento. b) De análise e reflexão sobre os dados, na qual participaram a supervisora e os colaboradores (psicólogos e filósofos) frente a proposta de um aconselhamento fundamentado na Daseinsanalyse, que Spanoudis (1978, p. 7-9) esclarece como: “[...] um caminho primeiramente de compreensão e participação e nesse sentido livre de explicações ou formulações teóricas [...] que sacrificam a autenticidade para satisfazer a qualquer custo a construção de uma teoria” (p. 24). A análise focalizou o que propiciava abertura de horizontes e reencontro das próprias possibilidades e o que não propiciava essa abertura nos sujeitos pesquisados. A preocupação foi desvelar de forma clara e simples o modo como aconselhadora/aconselhando ampliavam seus horizontes e reencontravam suas próprias possibilidades e os fatores externos à situação de aconselhamento que inseriam limites à abertura do aconselhando. c) Da proposta propriamente dita, de minha Tese de Doutorado intitulada Aconselhamento escolar uma proposta alternativa - atendimento ao "aluno dificil" - inspirada em Heidegger (1962), na análise do existir, do "ser com o outro" e dele "aproximar-se", Cap. IV de Ser e Tempo; em Boss e Condrau (1976); em Spanoudis (1978) - defendida na Pós-Graduação em Psicologia na Pontifícia Universidade Católica de São Paulo (PUC/SP), em 1982, e publicada em São Paulo pela Editora Loyola, em 1984, cuja característica e originalidade foi:

- expandir o sentido do "aproximar-se" à educação escolar, para registrar e analisar o uso que o aluno fazia de sua possibilidade de compreender o que lhe era ensinado;

- desvelar que percepção e entendimento de significados do aluno emergiam das relações que este fazia de suas condições existenciais de vida e não apenas do intelectual.

Resumidamente, a proposta de Aconselhamento Escolar - foco da Tese de Doutorado de buscar compreender o aconselhando - frisou a indispensabilidade de:

- lidar com dados vitais da experiência do aluno e de sua maneira específica de existir e não de especulações, conceitos e abstrações;

- valorizar o manifesto espontaneamente, buscando a unidade significativa percebida pelo aluno no vivido e no que aponta para o "devir";

- procurar compreender o significado específico daquele modo de existir e não causas ou explicações desse fenômeno, nem tendências previsíveis dedutivamente a partir de teorias ou explicações.

Um ano após finalizar o doutorado, fui convidada a lecionar na Habilitação de Ensino de pessoas com deficiência visual (DV), na Faculdade de Educação da Universidade de São Paulo (USP), área em que havia deixado de trabalhar - na "Fundação para o Livro do Cego no Brasil", no atendimento de pessoas com DV, e como professora desses alunos de escolas públicas - pouco depois do nascimento de meu filho e, na época desse convite, ele entrava na Graduação de Geologia desta mesma universidade. Assumir esse encargo e retornar à área da DV parecia-me temerário, de modo que busquei junto aos que trabalhavam com pessoas com DV (educadores e psicólogos) e em 
bibliografia especializada, nacional e estrangeira, informações sobre o desenvolvimento e a aprendizagem de pessoa com DV. Verifiquei com bastante surpresa que as respostas dos profissionais e a análise da bibliografia especializada mostravam que o desenvolvimento e a aprendizagem da pessoa com DV eram definidos pelos padrões adotados para videntes: o "conhecer" esperado tinha como pressuposto o "ver" e não se levava em conta as diferenças de percepção entre pessoa com DV e sem DV. A desconsideração dos autores a essas diferenças, supus, era determinada pela desatenção à predominância da visão, ou àquilo que havia ficado encoberto pela familiaridade, oculto pelo hábito, linguagem e senso comum, em uma cultura de videntes. Evidenciaram as respostas e as informações de bibliografia especializada e pesquisas: desatenção à individualidade, à singularidade e à especificidade do perceber. Em síntese, desconsideração às peculiaridades perceptuais na existência humana.

Na busca de destrinchar o porquê da adoção de padrões dos que dispõem da visão, para estudar aqueles que não dispõem da visão, a Fenomenologia da percepção de Merleau-Ponty (1999) indicou-me um caminho: ao assinalar, no prefácio de sua obra, o existir da fenomenologia como movimento, apontou o ater-se a padrões estabelecidos como a lacuna óbvia que levava à paralização dos profissionais e dos pesquisadores e seus textos; ao propor que a ciência retornasse ao solo do mundo sensível como é na própria vida para o próprio corpo - sentinela silenciosa dos atos e das palavras; ao sugerir que a investigação se voltasse para o sujeito no mundo como corpo no mundo - fonte de sentidos do sujeito, na totalidade da sua estrutura de relações com os outros e com as coisas ao seu redor; ao considerar o caráter inacabado da fenomenologia, não como índice de fracasso ou indefinição, mas sim do próprio reconhecimento de sua fertilidade, ressaltando para mim os seguintes pontos:

- a fenomenologia busca uma volta ao que é efetivamente vivido;

- os fenômenos não são coisas, mas acontecem num campo do qual o sujeito faz parte e juntos constituem um sistema;

- o que caracteriza a identidade do mundo percebido é a temporalidade, isto é, a síntese temporal por meio das próprias perspectivas do sujeito que percebe: a perspectiva presente anuncia a seguinte e retém a precedente num encadeamento. São várias e flexíveis perspectivas em movimentos de retomada do passado e abertura para o futuro;

- para compreender a percepção, é necessário evitar a alternativa natural (dos acontecimentos que se ligam entre si e causam uns aos outros) e a alternativa naturante (do sujeito que constitui o mundo e que dá sentido ao mundo). Em outras palavras, a perspectiva da objetividade (do mundo existente em si) ou da subjetividade (do mundo existente para si ou para uma consciência) - duas posições na qual o sujeito da percepção é ignorado.

As alternativas "natural" e "naturante" foram ultrapassadas por Merleau-Ponty ao considerar o sujeito no mundo como corpo no mundo - corpo que sente, que sabe, que compreende. Este "saber" do corpo, essa experiência original que é pré-consciente, pré-emocional, pré- 
categorial, faz reencontrar o corpo presente e total, aquele que não é um fragmento ou feixe de funções, mas um entrelaçamento de percepções e de dinamismo. Ao tomar a percepção como solo originário do conhecimento refere-se aos conteúdos particulares (especificidade) e às formas de percepção (generalidade). Os conteúdos são os dados sensoriais (visão, tato, audição) e a forma, a organização total desses dados, que é fornecida pela função simbólica ${ }^{2}$. Há uma dialética entre conteúdo e forma: não se pode organizar nada se não houver dados, mas estes, quando fragmentados (dissociados da função simbólica), de nada adiantam.

Evidenciava-se, assim, para mim, que: para compreender a pessoa e sua maneira de relacionar-se no mundo que a cerca deve-se sempre considerar suas estruturas perceptual e cognitiva, que exprimem ao mesmo tempo generalidade e especificidade (o conteúdo, a forma e a dialética entre ambas); para saber da percepção é necessário considerar o sujeito da percepção e de sua experiência perceptiva, em suas formas próprias de explorar e perceber.

Inspirada em Merleau-Ponty (1999), pesquisei o perceber de pessoas que não dispunham da visão, nas diretrizes da Fenomenologia da percepção.

Os limites encontrados, no conhecimento de profissionais que trabalhavam com pessoas com DV (educadores e psicólogos) e em bibliografia especializada, constituíram uma possibilidade que se oferecia à investigação: a de buscar saber sobre o perceber e o conhecer da pessoa com DV, para definir diretrizes à sua educação. Optei, assim, por um projeto que focalizasse a pessoa com DV em situação educacional e, na qualidade de docente nas disciplinas "Avaliação do deficiente visual" e "Orientação educacional do deficiente visual", decidi por uma pesquisa que fosse feita junto a professoras especializadas, a partir de vivências destas com grupos de alunos com DV.

Nas diretrizes do método sugerido em Fenomenologia da percepção, assumi as dificuldades de registrar o vivido em sua totalidade, sem fragmentar o que emergisse dos participantes e de suas relações, por meio de uma descrição direta da experiência, com palavras do cotidiano e não de explanação, ou forma de falar própria da ciência, de uma consciência sofisticada. Como o interesse era na experiência da pessoa com DV, era registrado o que ela dizia, sua entonação de voz, seus gestos, suas expressões, nas diferentes situações, bem como junto aos demais participantes do grupo, descrevendo-os também.

A sempre presente questão - de saber se a descrição se referia ao que se mostrava e não a impressões, experiências anteriores, valores, teorias - esclarecia-se nas discussões de "supervisão", na qual compartilhavam a pesquisadora e as auxiliares de pesquisa, procurando identificar naquela que descrevia o ocorrido o que dela se interpunha na situação, impedindo-a de perceber como se mostrava a pessoa com DV e os demais participantes em suas relações.

Nos "encontros de discussões" e na "formação de auxiliares de pesquisa, professoras especializadas e aconselhadoras" apareceram recursos para compreender a própria posição

\footnotetext{
${ }^{2}$ Função simbólica, como a entende Piaget (1971, p. 14): “mecanismo comum aos diferentes sistemas de representações e como mecanismo individual cuja existência prévia é necessária para tornar possíveis as interações do pensamento entre indivíduos... papel essencial na elaboração de conceitos".
} 
frente ao outro: saber dos próprios valores, sentimentos, conhecimentos; reconhecer o próprio universo de símbolos $^{3}$ e a ideologia ${ }^{4}$ da cultura a que se pertence, requerido para a interpretação ${ }^{5}$.

O Projeto de Pesquisa constituiu-se das etapas que seguem:

a) 1985 - Preparatória. Participante: pesquisadora. Matéria-prima: livros e revistas referentes a pessoa com DV. Objetivo: levantar as caraterísticas das pessoas com DV para definir sua orientação educacional; organizar o projeto de pesquisa.

b) 1986 - Vivencial. Participantes: pesquisadora e auxiliares de pesquisa (aconselhadoras e professoras especializadas) e grupos de pessoas com DV. Matéria-prima: o ocorrido nas vivências nos grupos de DV. Constituída de encontros de discussão e de supervisão sobre os grupos de pessoas com DV, com duração de dois semestres: da $2^{\mathrm{a}}$ quinzena de fevereiro à $1^{\mathrm{a}}$ semana de julho e da $1^{\text {a }}$ semana de agosto à $1^{\mathrm{a}}$ de dezembro. Os encontros e as supervisões perfaziam no total quatro horas semanais. Objetivo dos grupos de discussão junto às auxiliares de pesquisa: experienciar o caminho da pessoa com DV perceber o mundo ao derredor, explorando objetos sem o uso da visão e descrevendo essa experiência perceptiva. Objetivo da supervisão: descrever o vivido nos grupos de pessoas com DV, desvelar as atitudes da professora e da aconselhadora junto às crianças individualmente, ao grupo como um todo e refletir sobre o que havia ficado obscuro das crianças e das relações entre os participantes, para tornar claros esses pontos, em situações futuras semelhantes.

A participação das auxiliares de pesquisa requereu formação específica.

- Duas professoras especializadas: uma recém-formada na "Habilitação de Ensino a pessoas com DV", na Faculdade de Educação da USP (FEUSP), com dois anos de experiência em sala de recursos; uma totalmente cega, responsável há sete anos pela sala de recursos, onde se realizou a pesquisa, que, com sua experiência sem a visão, contribuiu muito para a reflexão sobre pontos obscuros e recursos para trabalhar com a pessoa com DV.

- Três aconselhadoras tiveram um ano (no mínimo) de preparação específica em aconselhamento fundamentado na Daseinsanalyse, incluindo grupo de estudos de textos teóricos e relatos de experiências.

\footnotetext{
${ }^{3}$ Símbolo - estrutura de significação em que um sentido direto, primário literal, designa por acréscimo outro indireto, secundário figurado que não pode ser entendido senão por meio do primeiro.

${ }^{4}$ Ideologia - entendida como lógica da ocultação e dissimulação que se baseia na ideia de uma Sociedade e não no que acontece na Sociedade. As pessoas pensam, sentem, agem guiadas por uma ilusão da Sociedade, sem estarem atentas ao que acontece. A consciência fica na aparência e forja explicações a partir da ideia de Sociedade.

${ }^{5}$ Interpretação - trabalho do pensamento que consiste em decifrar o sentido aparente, em desdobrar os sinais de significação literal... há interpretação onde houver sentido múltiplo e é na interpretação que a pluralidade de sentidos torna-se manifesta.

Esses conceitos são aqui definidos no sentido que o faz Ricoeur (1978).
} 
- Objetivos da formação: aprofundar o autoconhecimento através de vivências; ampliar a percepção do outro por meio de exercícios de descrição e discussão de situações vividas; clarear os próprios significados em situações de atendimento do aluno em escola pública; buscar recursos para aproximar-se e compreender o aluno com DV.

c) 1987 - Análise. Participantes: pesquisadora e analistas ${ }^{6}$. Matéria-prima: relatos ${ }^{7}$ das aconselhadoras. Objetivo: desvelar o fenômeno, "o perceber e o relacionar-se da pessoa com DV e os recursos que a auxiliam nesses aspectos". Como análise fenomenológica, essa fase não se limitou a uma descrição, mas constituiu-se, simultaneamente, da tarefa de interpretação (tarefa da hermenêutica), que consiste em pôr a descoberto os elementos menos aparentes, aqueles que o fenômeno tem de mais fundamental.

A análise evidenciou a riqueza do uso específico dos outros sentidos pelas pessoas que não dispunham da visão, efetivando minha Tese de Livre Docência intitulada "O perceber e o relacionar-se do deficiente visual - orientando professores especializados", defendida na FEUSP em 1990, e publicada em Brasília pela Coordenadoria Nacional para integração da pessoa portadora de deficiência (Corde) em 1994, com o mesmo título. A continuidade dessa investigação levou a ampliar e aprofundar o perceber dos que dispõem de todos os sentidos.

Prossegui com diversos projetos de atividades e pesquisas sobre percepção de pessoas com e sem DV, em variadas situações. Na FEUSP, de 1991 a 1993, em Cursos de Graduação e de Pós-Graduação, entre os quais cabe destacar os que seguem: a) "Perspectivas para pessoas com DV", subprojetos ligados à Graduação, sob a responsabilidade de artistas, com duração de dois anos: "Expressão corporal para pessoas com DV", oferecido a adultos, com aulas em sala da FEUSP, ministradas pela professora voluntária Leslie Gimenez, graduada em Filosofia pela USP e bailarina da Escola de Bailado Municipal; "Cerâmica para pessoas com DV", oferecido pelo professor voluntário Álvaro Picanço, artista plástico, com aulas no Centro Cultural Vergueiro, por um ano, para adultos e em sala da FEUSP, por um ano, para crianças. b) "Seminários", disciplina optativa oferecida na PósGraduação em Educação a pessoas que dispunham de todos os sentidos. Objetivo: oferecer abordagem globalizante da percepção, com a contribuição de especialistas em diferentes concepções teóricas propiciando a complementariedade de embasamentos epistemológicos; iniciar um grupo de estudos interuniversidades para realização de pesquisas sobre percepção. As aulas e as discussões contaram com professores da USP (Faculdade de Educação, de Psicologia e de Arquitetura e Urbanismo), da PUC/SP, da Universidade São Marcos e da Universidade Johns Hopkins, dos Estados Unidos.

Aprofundei estudos sobre fenomenologia da percepção em algumas universidades, umas por um certo período e outras desde que tiveram início até o presente, conforme mostram os dados a seguir:

- Universidade de São Paulo - FE (1993-2016);

- Universidade São Marcos - Unimarco (1994);

\footnotetext{
${ }^{6}$ Analistas - formadas em Curso de Aconselhamento, embasado na Dasainsanalyse, realizado no Instituto Sedes Sapientiae em anos anteriores.

${ }^{7}$ Relato - registro por escrito de todo vivido no grupo de DV, no período de um ano letivo: de cada sessão uma descrição do vivido, os comentários da Aconselhadora articulando o que emergiu, as preocupações a partir dos comentários, sobre pontos a que se deve estar atenta futuramente, em situações semelhantes.
} 
- Universidade Presbiteriana Mackenzie - UPM (2010-2016).

Na qualidade de docente pesquisadora do Programa de Pós-Graduação "Educação, Arte e História da Cultura" (EAHC) na UPM, em 2010 ofereci a disciplina eletiva, para alunos de mestrado e doutorado, "PERCEPÇÃO: sensibilidade e arte na ação educacional - impasses e perspectivas", com a duração de um semestre letivo. Esta disciplina oferecida anualmente, de 2010 até o presente ano de 2016, constituída de vivências, leituras e discussões sobre os caminhos e as diferentes maneiras de cada um entrar em contato com o que o cerca, fazer uso de sua sensibilidade, obter informações e elaborar esses dados para organizar e compreender o derredor, tem como foco: explorar, aprofundar e desvelar a flexibilidade e as possibilidades da adaptabilidade humana; despertar questões sobre a complexidade de conhecimentos imbricadas nas possibilidades da existência humana; integrar diferentes áreas de estudos em busca de apropriação para compreender o que favorece o desenvolvimento, a aprendizagem, a integração pessoal/social e autonomia de um ser humano. Os objetivos da disciplina: oferecer recursos teóricos e práticos para conhecer o embasamento filosófico da dialética do perceber na existência; refletir sobre a fundamentação teórica oferecida e seu significado para trabalhos na própria área de atuação; aproximar-se de uma pessoa para saber sobre seu perceber e conhecer; discutir sua experiência perceptiva e as implicações de desenvolver sua ação profissional na própria área de atuação.

O aprofundamento dos estudos e os projetos desenvolvidos na disciplina têm ilustrado a disseminação da fenomenologia existencial da educação formal para as relações sociais na vida, na diversidade de áreas do conhecimento. Dois livros (Figuras 1 e 2), por mim organizados, apresentam pesquisas e atividades desenvolvidas, embasadas na obra de Merleau-Ponty, por alunos desta disciplina nos anos de 2010 a 2012.

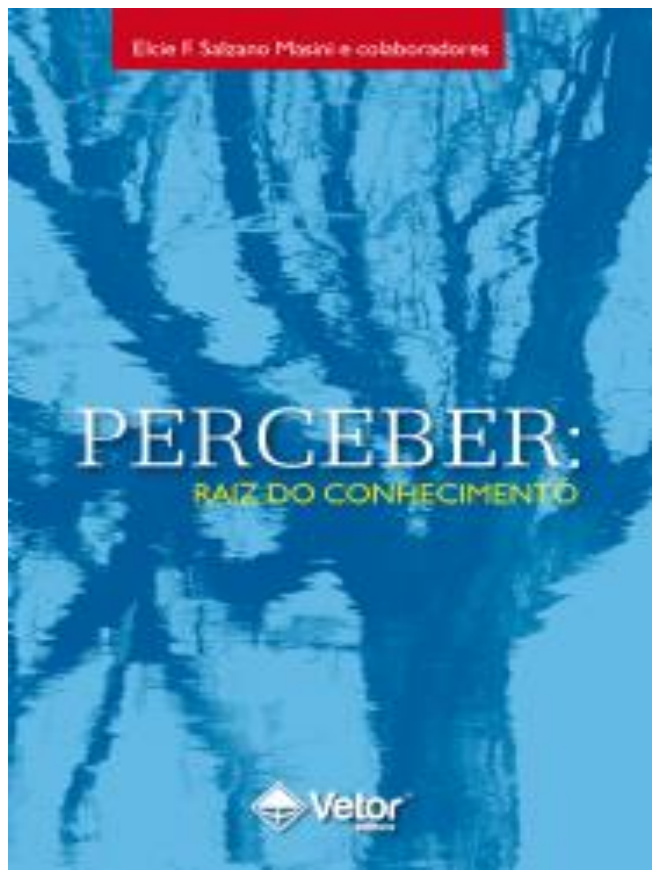

Figura 1. Perceber: Raiz do conhecimento. São Paulo: Vetor, 2012. 


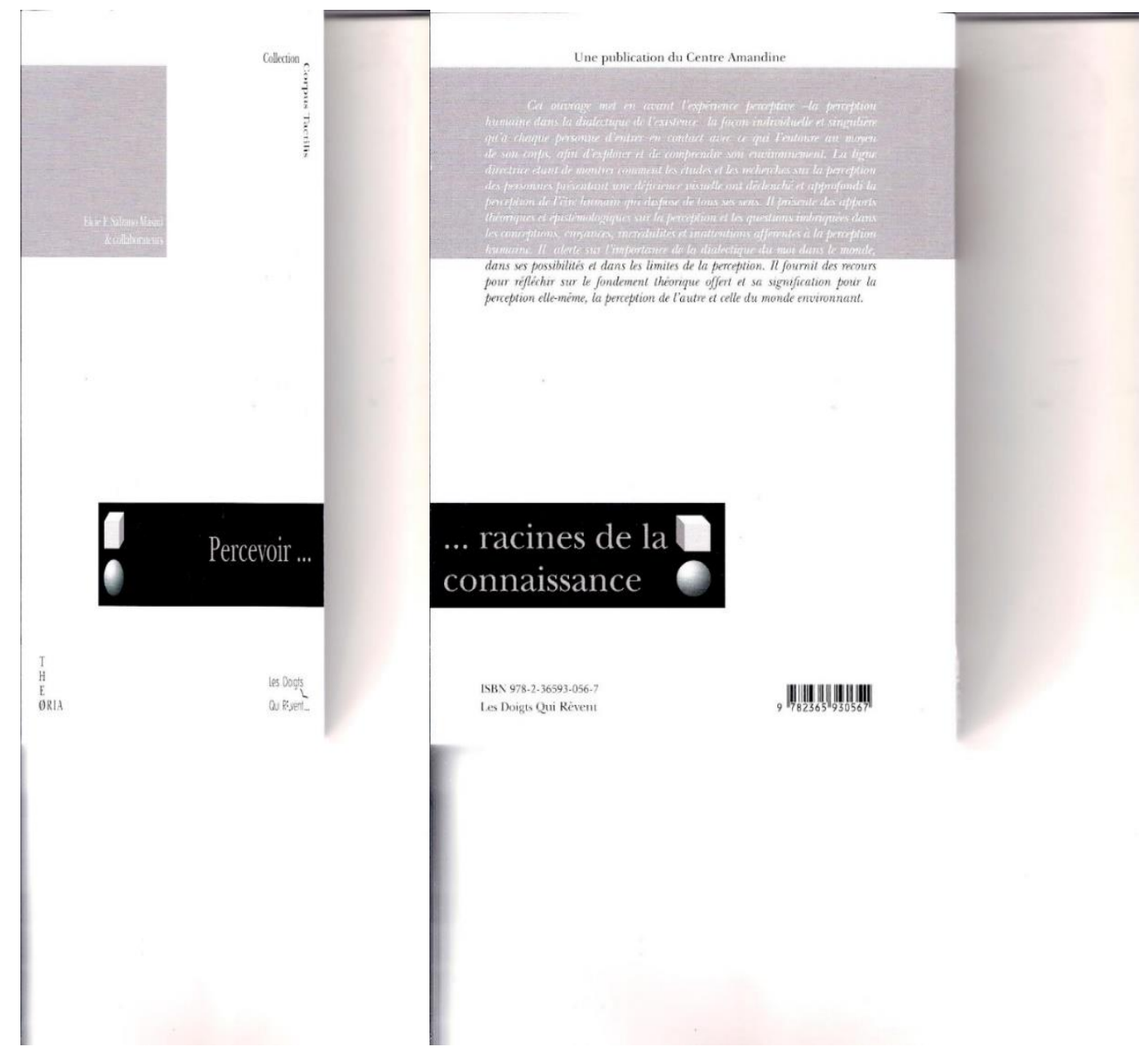

Figura 2. Percevoir... racines de la connaissance (2016). Dijon: Les Doigts Qui Révent, 2016.

A síntese reduzida de textos de alunos, que estão no livro, sobre suas pesquisas e atuação em diferentes áreas de conhecimento é a seguir apresentada, com a intenção de ilustrar a diversidade do perceber, no existir e a disseminação da fenomenologia existencial de Merleau-Ponty da educação formal para as relações sociais na vida.

\section{EDUCAÇÃO PATRIMONIAL - UM OUTRO OLHAR - Frederico Fernando Souza.}

Objetivo: Fomentar a prática e o desenvolvimento da percepção sobre os bens culturais que permeiam o dia a dia nas escolas, na experiência estética: a experiência do olhar, tocar, sentir é única para cada um estabelecer a sua própria compreensão de mundo e dar sentido a ele e às coisas que o compõem; entendimento consistente e participativo sobre a preservação das memórias e das identidades que fazem parte do Patrimônio Cultural, alinhavado com fios de percepção e de sensibilidade. 


\section{PERCEBER E SENTIR - ARTE CIÊNCIA - Ítalo Francisco Curcio.}

Objetivo: Pensar sobre Arte e Ciência, considerando como estas manifestaramse e continuaram manifestando-se por meio de seu protagonista, o ser humano, ao longo de sua historicidade, mencionando que os significados e sentidos que o ser humano foi atribuindo à Arte e à Ciência dependeram da própria cultura em que estava inserido. Evidenciou que Arte e Ciência possuem estreitos laços de origem, diretamente ligados à configuração do ser humano como ser social e que a manifestação e desenvolvimento se dão pelo seu sentir e pelo seu perceber.

\section{A EXPERIÊNCIA SENSORIAL EM UM SUPERMERCADO - Roseli Behaker Garcia.}

Objetivo: Focalizar o uso de diferentes vias sensoriais, a fim de priorizar outros sentidos além da visão. Perceber é complexo, porém, apaixonante, desbravador e enriquecedor. Registros escritos, de experiência perceptiva nas diferentes sessões do supermercado, tornaram mais claras as ideias de Merleau-Ponty (1999): a dinâmica do corpo como fonte dos sentidos; a abertura das vias sensoriais para o mundo ao seu derredor, para um perceber que se renova e se transforma sempre.

PERCEPÇÃO E MINISTÉRIO PASTORAL: uma experiência pessoal - Filipe Costa Fontes.

Objetivo: Mostrar como o estudo da Fenomenologia da Percepção de MerleauPonty levou a considerar questões importantes relacionadas à atividade pastoral e apontar pontos relevantes para esta atividade: o homem estar em relação ativa no mundo, no perceber as coisas ao seu redor, em dinâmica relação com o outro, na construção de sua identidade; a valorização do indivíduo, chave para o ministério pastoral, no ensino e no aconselhamento.

\section{O DESPERTAR DA PERCEPÇÃO NA EDUCAÇÃO INFANTIL: CAMINHOS - Débora Cardoso.}

Objetivo: Desenvolver uma experiência pedagógica de convívio de educadores e crianças, de quatro meses a quatro anos de idade, da Creche Betel, da Secretaria de Educação da cidade São Bernardo do Campo, SP, visando: sensibilizar os envolvidos no processo educacional sobre a relevância da atuação natural e ativa; oferecer situações vivenciais individuais e de grupo, respeitando a curiosidade e o interesse das crianças, para resgatar e ampliar o uso de seu corpo na exploração do derredor, propiciando que atribua seus próprios sentidos; fornecer informações sobre a Fenomenologia da Percepção, de Merleau-Ponty, embasamento da experiência educacional da creche. 


\section{A MÃO E O TOCAR NA SURDOCEGUEIRA: MUITO ALÉM DA \\ EXPLORAÇÃO TÁTIL - Rosangela Nezeiro da Fonseca Jacob.}

Objetivo: Entender sobre alguns sentidos - visão, audição, tato - para discutir o uso das mãos para percepção do mundo pela pessoa surdocega. O sistema tátil é muito mais complexo do que concebe o senso comum. Não é apenas a pele que recobre um corpo e recebe passivamente os estímulos, pois a mão explora não apenas pela sensação tátil, mas pelo movimento, preensão, vontade, desejo: “[...] exprime a aventura do eu, para lá das fronteiras e da finitude encarnada pelo seu organismo" (Brun, 1991, p. 27). A mão fala, ouve, vê informações de um mundo complexo, Como defende Brun (1991): "o verdadeiro órgão da existência" (p. 23). Sem as mãos não se poderia encontrar o mundo e trazê-lo para perto. 


\section{Referências}

Ausubel, D. P. (1963). The psychology of meaning verbal learning: An introduction to scholl learning. New York, NY: Grune and Stratton.

Boss, M. (1976). Encontro com Boss: Daseinsanalyse. Revista da Associação Brasileira de Daseinsanalyse, 2, 5-21.

Boss, M. (1979). A noite passada eu sonhei. São Paulo, SP: Summus.

Boss, M., \& Condrau, G. (1976). Análise existencial: Daseinsanalyse. Revista da Associação Brasileira da Daseinsanalyse, 2, 5-24.

Heidegger, M. (1962). Being-in-the-world as being with and being one's self: The “they”. In M. Heidegger, Being and time (pp. 113-163). New York, NY: Row.

Masini, E. F. S. (1984). Aconselhamento escolar uma proposta alternativa: Atendimento ao "aluno dificil". São Paulo, SP: Loyola.

Masini, E. F. S. (1994). O perceber e o relacionar-se do deficiente visual: Orientando professores especializados. Brasília, DF: Coordenação Nacional para a Integração da Pessoa com Deficiência.

Masini, E. F. S. (Org.). (2012). Perceber: Raiz do conhecimento. São Paulo, SP: Vetor.

Masini, E. F. S. (Org.). (2016). Percevoir... racines de la connaissance. Dijon: Les Doigts qui Rêvent.

Merleau-Ponty, M. (1999). Fenomenologia da percepção. São Paulo, SP: Martins Fontes. (Originalmente publicado em 1945).

Minkowski, E. (1968). Le temps vécu. Neuchatel: Instituit des Science de l’educaction de Université de Genêve.

Piaget, J. (1971). A formação do símbolo na criança: Imitação, jogo e sonho, imagem e representação. Rio de Janeiro, RJ: Zahar.

Ricoeur, P. Conflito das interpretações: ensaios de hermenêutica. Rio de Janeiro, Imago, 1978.

Spanoudis, S. (1978) A tarefa do aconselhamento e orientação a partir da Daseinanalyse. Daseinanalyse (4), 7-26.

Spanoudis, S. (1981). Todos nós... ninguém. São Paulo, SP: Moraes. 